Fixed Point Theory, 22(2021), No. 2, 495-510

DOI: $10.24193 /$ fpt-ro.2021.2.33

http://www.math.ubbcluj.ro/ nodeacj/sfptcj.html

\title{
FIXED POINT RESULTS IN LOCALLY CONVEX SPACES WITH $\tau$-KREIN-ŠMULIAN PROPERTY AND APPLICATIONS
}

\author{
FATIMA BAHIDI*, BILEL KRICHEN** AND BILEL MEFTEH*** \\ *Department of Mathematics, Faculty of Sciences of Sfax, University of Sfax, \\ Road of Soukra Km 3.5, B.P. 1171, 3000, Sfax, Tunisia \\ E-mail: bahidi.fatima@yahoo.com \\ **Department of Mathematics, Faculty of Sciences of Sfax, University of Sfax, \\ Road of Soukra Km 3.5, B.P. 1171, 3000, Sfax, Tunisia \\ E-mail: krichen_bilel@yahoo.fr \\ *** Department of Mathematics, Faculty of Sciences of Sfax, University of Sfax, \\ Road of Soukra Km 3.5, B.P. 1171, 3000, Sfax, Tunisia \\ E-mail: bilel.mefteh@gmail.com
}

\begin{abstract}
In this paper, we present some new fixed point theorems in a locally convex space $X$ with the so called $\tau$-Krein-Šmulian property considering the concept of $\Phi_{\Lambda}^{\tau}$-measures of noncompactness, where $\tau$ is a weaker Hausdorff locally convex topology of $X$. Further, we apply our results to discuss the existence of solutions for a nonlinear functional integral equation in the Lebesgue space $L^{1}$.

Key Words and Phrases: $\Phi_{\Lambda}^{\tau}$-measure of noncompactenss, $\tau$-sequentially continuous, $\tau$-KreinŠmulian property, angelic space.
\end{abstract}

2020 Mathematics Subject Classification: 47H10, 47H09, 47H30.

\section{REFERENCES}

[1] J. Appell, E. De Pascale, Some parameters associated with the Hausdorff measure of noncompactness in spaces of measurable functions, Unione Matematica Italiana Bollettino B, 3(1984), no. 2, 497-515.

[2] J. Appell, P. Zabrejko, Nonlinear Superposition Operators, Cambridge Univ., 1990.

[3] O. Arino, S. Gautier, J. Penot, A fixed point theorem for sequentially continuous mappings with application to ordinary differential equations, Funkcialaj Ekvacioj 27(1984), no. 3, 273-279.

[4] J. Banaś, Applications of measures of weak noncompactness and some classes of operators in the theory of functional equations in the Lebesgue space, Nonlinear Analysis: Theory, Methods and Applications, 30(1997), no. 6, 3283-3293.

[5] J. Banaś, A. Ben Amar, Measures of noncompactness in locally convex spaces and fixed point theory for the sum of two operators on unbounded convex sets, Comment. Math. Univ. Carolin., 54(2013), no. 1, 21-40.

[6] A. Ben Amar, A. Jeribi, M. Mnif, Some fixed point theorems and application to biological model, Numerical Functional Analysis and Optimization, 29(2008), no. 1-2, 1-23.

[7] A. Ben Amar, M. Mnif, Leray-schauder alternatives for weakly sequentially continuous mappings and application to transport equation, Mathematical Methods in the Applied Sciences, 33(2010), no. $1,80-90$. 
[8] G. Cain, M. Nashed, Fixed points and stability for a sum of two operators in locally convex spaces, Pacific Journal of Mathematics, 39(1971), no. 3, 581-592.

[9] G. Darbo, Punti uniti in trasformazioni a codominio non compatto, Rendiconti del Seminario Matematico della Universita di Padova, 24(1955), 84-92.

[10] F.S. De Blasi, On a property of the unit sphere in a Banach space, Bulletin Mathématique de la Société des Sciences Mathématiques de la République Socialiste de Roumanie, (1977), 259-262.

[11] K. Floret, Weakly Compact Sets: Lectures Held at SUNY, Buffalo, in spring 1978, volume 801, Springer, 2006.

[12] J. Garcia-Falset, Existence of fixed points and measures of weak noncompactness, Nonlinear Analysis: Theory, Methods and Applications, 71(2009), no. 7-8, 2625-2633.

[13] M.A. Geraghty, On contractive mappings, Proceedings of the American Mathematical Society, 40(1973), no. 2, 604-608.

[14] A. Jeribi, B. Krichen, Nonlinear Functional Analysis in Banach Spaces and Banach Algebras: Fixed Point Theory under Weak Topology for Nonlinear Operators and Block Operator Matrices with Applications, Chapman and Hall/CRC, 2015.

[15] M. Krasnoselskii, P. Zabreiko, E. Pustylnik, P. Sobolevskii, Integral Operators in Spaces of Summable Functions. Noordhoff, Leyden, 1976.

[16] R.E. Megginson, An Introduction to Banach Space Theory, vol. 183, Springer Science and Business Media, 2012.

[17] D. O'Regan, Fixed-point theory for weakly sequentially continuous mappings, Mathematical and Computer Modelling, 27(1998), no. 5, 1-14.

[18] B.N. Sadovskii, A fixed-point principle, Functional Analysis and Its Applications, 1(2)(1967), 151-153.

[19] F. Wang, H. Zhou, Fixed point theorems and the Krein-S̆mulian property in locally convex spaces, Fixed Point Theory and Applications, 2015(2015), no. 1, 154.

Received: April 18, 2019; Accepted: July 10, 2019. 
FIXED POINT RESULTS IN LOCALLY CONVEX SPACES 